\title{
Effects of Standing Aids on Lumbar Spine Posture and Muscle Activity in the Lumbar Spine and Hip during Prolonged Standing
}

\author{
Hyeon-Jin Kim • Young-Eun $\mathrm{Choi}^{1 \dagger}$ \\ Department of Radiological Science, Kaya University \\ ${ }^{1}$ Department of Physical Therapy, Kaya University
}

Received: January 23, 2019 / Revised: January 31, 2019 / Accepted: March 6, 2019

(c) 2019 J Korean Soc Phys Med

\section{| Abstract |}

PURPOSE: This study was conducted to compare different standing postures with the use of standing aids for lumbar spine posture and muscle activity, and to identify the most desirable standing posture.

METHODS: The lumbopelvic angle was assessed based on static radiographic measurement on the sagittal plane. Lumbar lordosis, lumbosacral lordosis, and the intervertebral joint angle at L1/L5 and L5/S1 were measured using radiography in three standing postures (standing on level ground, standing with one foot on a platform, and standing on a sloped surface). In addition, muscle activity was measured using surface electromyography to examine the cocontraction of the lumbar and hip muscles.

RESULTS: Lumbar lordosis, lumbosacral lordosis, and L5/S1 intervertebral joint flexion occurred with one foot on the platform. No significant differences were found between standing on a sloped surface and standing on level ground.

†Corresponding Author : Young-Eun Choi choiye00@naver.com, http://orcid.org/0000-0002-1419-8519

This is an Open Access article distributed under the terms of the Creative Commons Attribution Non-Commercial License (http://creativecommons.org/licenses/by-nc/3.0) which permits unrestricted non-commercial use, distribution, and reproduction in any medium, provided the original work is properly cited.
However, muscle co-contraction was reduced with the use of standing aids.

CONCLUSION: This study demonstrated that standing with a foot on a platform induced lumbar lordosis, but that there was no significant difference between standing on a sloped surface and standing on level ground. However, muscle co-contraction was reduced with the use of standing aids. Based on the motor control pattern as a predictor of LBP, the use of standing aids would help workers during prolonged standing.

Key Words: Lordosis, Standing aid, Muscle co-contraction

\section{Introduction}

Low back pain (LBP) occurs in $>80 \%$ of adults at least once in their lifetimes, and the incidence increases with the industrialization of society [1]. According to an analysis of the status of industrial accidents, $61.9 \%$ of all individuals with job-related illnesses have musculoskeletal disorders, including job-induced musculoskeletal burden and LBP [2]. The causes of non-specific LBP are varied, as different tissues in the lumbar spine can cause pain [3]. One of the causes of non-specific LBP is performing a task that requires prolonged standing [4]. In a previous study, as many as $71 \%$ of study subjects had LBP while standing 
for 2 hours [5]. In another study, the incidence of LBP was approximately doubled in workers who needed to stand in a restricted posture while performing their jobs when compared with those who were free to sit at work [6]. In an investigation in which subjects without a history of low back injury or treatment for LBP were instructed to perform a task during prolonged standing, $41 \%$ presented with pain after 15 minutes, and this percentage increased to $71 \%$ after 45 minutes [7].

To maintain normal standing posture, the muscles involved in trunk and pelvic stability must function normally. Movements made during a typical standing posture usually occur on the frontal plane, and the center of pressure on the medial-lateral plane is controlled to a large degree by the hip abductors and adductors [8]. The more the hip muscles on the right side are activated, the more the body weight shifts to the lower limb on the same side, and consequently, the weight load on the left lower limb decreases [9]. Muscle activation patterns differ between individuals with pain and those without pain while maintaining a standing posture. In individuals without pain, the right and left gluteus medius (GM) are activated in a reciprocal pattern, whereas the same muscles co-contract in those with pain [4].

To reduce the occurrence of LBP during standing at work, use of standing aids designed to change foot position is recommended [10]. In a study that compared low back muscle activities during standing with one foot on a 20-cm-high platform with that during standing with two feet on the ground, lumbar flexion and low back muscle activity increased in the former posture [11]. Prolonged standing on a surface with a $16^{\circ}$ slope reduced pain by $59.4 \%$ [12], and standing on an elevated surface or a declining sloped surface was effective for lumbar spine flexion [13]. The occurrences of GM co-contraction and LBP were reduced when standing on a sloped surface when compared with standing on a flat surface [14].

The benefits of mild flexion are suggested by the impact of standing aids on lumbar spine and pelvic posture using a sloped surface and elevating one leg on a platform [11-13]. However, the focus of studies conducted to date was interventional approaches for postural changes in the standing posture, while few studies have investigated the effects of such interventions on the muscle activation pattern. Accordingly, the present study was conducted to examine lumbar spine posture and muscle activity in various standing postures with the use of standing aids and to identify the most desirable standing posture.

\section{Methods}

\section{Study subjects}

The study subjects were 21 healthy adults (11 men and 12 women) who were fully informed of the study purposes and procedure and voluntarily consented to participate. Individuals unable to stand for at least 2 hours, those with a history of medical intervention for LBP, and those with a history of surgery in the lumbar spine or hip were excluded from the study. The mean age, height, and weight of the study subjects were $21.48 \pm 1.60$ years, $167.19 \pm 7.92 \mathrm{~cm}$, and $64.43 \pm 10.93 \mathrm{~kg}$, respectively.

\section{Measurement}

Surface electromyography (BTS FREE EMG 300, BTS Bioengineering, Italy) was used to measure lumbar and hip muscle activities during standing. To minimize skin impedance, the regions to which electrodes would be applied were shaved and cleaned with alcohol. Next, two pairs of disposable surface EMG electrodes were attached to the left and right lumbar erector spinae (LES) and GM. On the LES, electrodes were attached to regions $4 \mathrm{~cm}$ horizontally away from the L3 spinous process. On GM, the electrodes were attached to regions located approximately one third from the greater trochanter to the iliac crest. The sampling rate of the EMG signals was set to $1000 \mathrm{~Hz}$, and 20 to $400 \mathrm{~Hz}$ bandpass filters were used. 


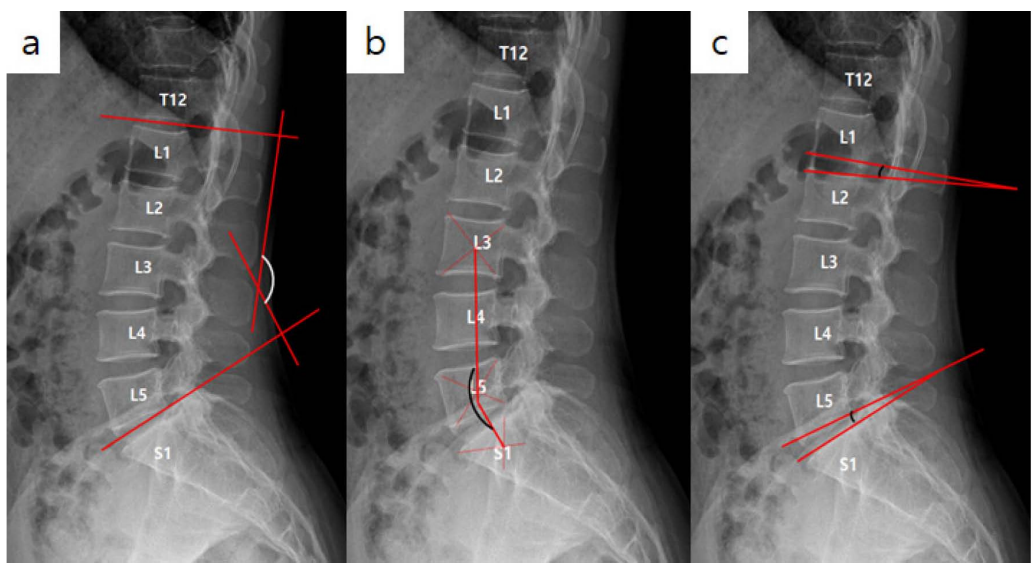

Fig. 1. Lateral radiographic images (a: lumbar lordosis, b: lumbosacral lordosis, c: lumbosacral intervertebral joint angle)

Maximal voluntary isometric contractions (MVIC) were performed for 5 seconds to normalize the EMG data. The MVIC measurement in the LES was performed with the subjects lying in a prone position on a table. First, the subjects were instructed to position themselves such that the anterior superior iliac spine was at the edge of the table, with the trunk falling outside the table and their arms crossed on their chest and bent toward the ground. As the subject was unbending the trunk from the position, the researcher applied resistance. MVIC measurement in the GM was performed by applying resistance during hip abduction, with the subjects lying on their side. Muscle co-contraction, which refers to simultaneous activation of the right and left LES and GM, was calculated using the following formula: [(less active muscle/more active muscle) $\mathrm{X}$ (sum of the integrated activity of both muscles)] [15].

The lumbopelvic angle was assessed on the basis of static radiographic measurement on the sagittal plane. To assess the lumbar lordosis angle, the angle formed by the line parallel to the superior end plate of L1 and the line parallel to the superior end plate of L5 (the bottommost disk in the lumbar area where kyphosis begins with respect to the sacrum) was measured. The lumbosacral lordosis angle was assessed by measuring the posterior angle formed by the line connecting the centers of the vertebral bodies of L3 and L5, and the line connecting the centers of L5 and S1. The intervertebral joint angles of L1/L2 and L5/S1 were assessed by measuring the angle formed by the line parallel to the inferior end plate of L1 (or L5) and the line parallel to the superior end plate of L2 (or S1) (Fig. 1).

In the study, the following three standing postures were used while muscle activity and radiographic measurements were taken:

- Standing with two feet in parallel on a flat surface (ground)

- Standing with one foot on a platform (platform). The height of the platform was modulated so that the angle between the thigh and trunk would be $135^{\circ}$ [16] (Fig. 2).

- Standing on a sloped surface (sloped). The slope was at a $16^{\circ}$ angle, and the subjects were standing on the downward slope [4].

\section{Statistical analyses}

Experimental data were analyzed using PASW ver. 18.0. For descriptive statistics, means and standard deviations are presented. To compare lumbar and lower limb muscle activities and lumbar lordotic curves among the standing postures, one-way ANOVA with repeated measures was conducted. The statistical significance level, $a$, was set at .05 . 


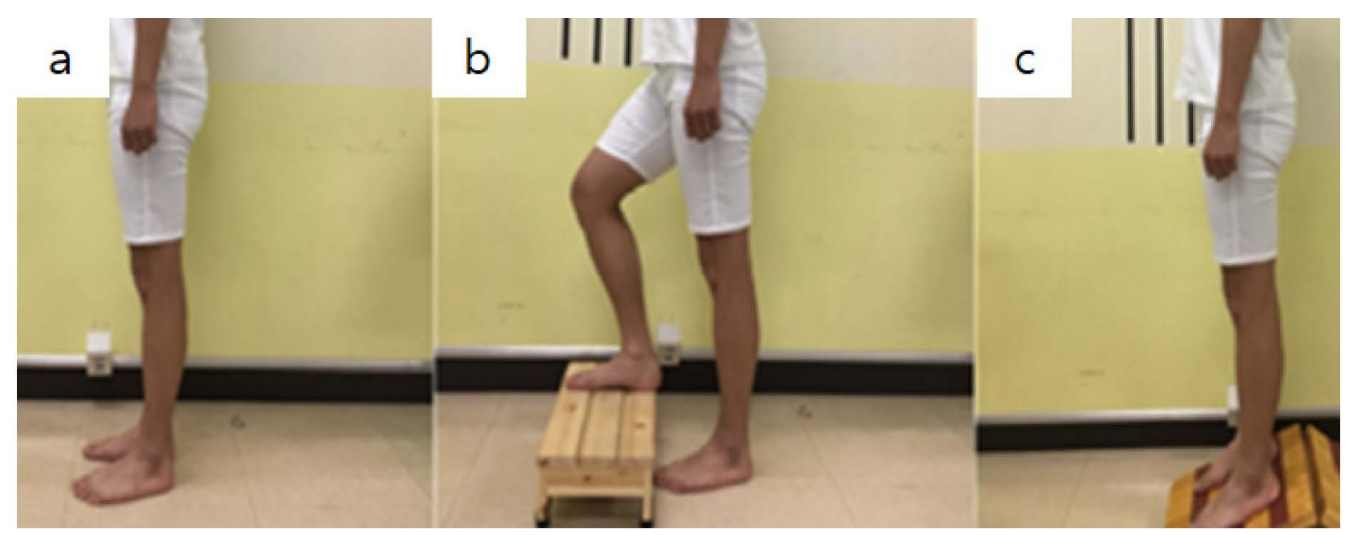

Fig. 2. Standing conditions (a: ground, b: platform, c: sloped)

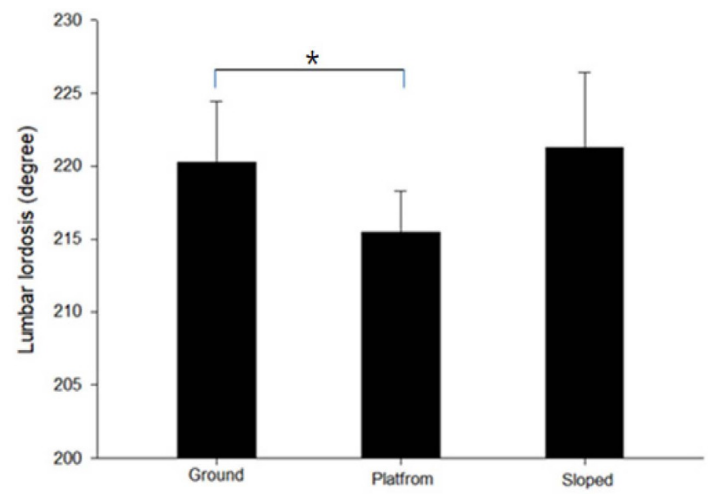

Fig. 3. Lumbar lordosis in three standing conditions

\section{Results}

There were significant differences among the lumbar lordosis measured for the three different standing positions $(\mathrm{p}=.003)$ (Fig. 3). The lumbar lordosis angle was more extended when standing on the ground than when standing with one foot on a platform $(p=.013)$. There was a significant difference between the lumbosacral lordosis angle when standing on the ground than when standing on a platform ( $\mathrm{p}=.002)$ (Fig. 4). Additionally, significant differences were evident in the L1/L5 ( $p=.006)$ and $\mathrm{L} 5 / \mathrm{S} 1$ $(\mathrm{p}=.004)$ intervertebral joint angles measured for the three different standing posture. There was also a significant difference between the L1/L5 intervertebral joint when

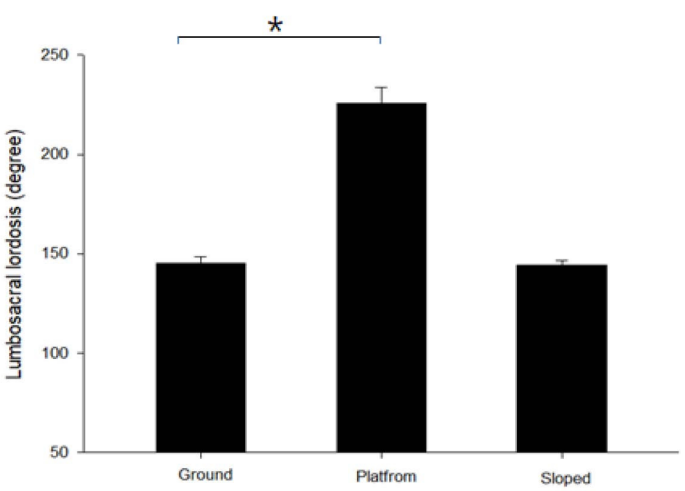

Fig. 4. Lumbosacral lordosis in three standing conditions

standing on the ground and standing on a platform $(\mathrm{p}<.001)$. Finally, there was a significant difference between the L5/S1 intervertebral joint when standing on the ground and standing on a platform ( $\mathrm{p}=.001)$ (Table 1) (Fig. 5).

The right and left LES co-contraction value was significantly higher when standing on the ground than any other standing position $(\mathrm{p}<.001)$. The right and left gluteus medius co-contraction index was higher when standing on the ground than in any other standing position $(\mathrm{p}<.001)$ (Table 2) (Fig. 6). 
Table 1. Average Lumbar Lordosis Values in Three Standing Conditions

\begin{tabular}{cccc}
\hline Lumbar lordosis & Ground & Platform & Sloped \\
\hline Lumbar lordosis $\left(^{\circ}\right)$ & $221.242 \pm 5.603^{\mathrm{b}}$ & $216.294 \pm 5.193^{\mathrm{a}}$ & $218.290 \pm 6.132$ \\
Lumbosacral lordosis $\left(^{\circ}\right)$ & $149.792 \pm 5.214^{\mathrm{b}}$ & $155.942 \pm 5.202^{\mathrm{a}}$ & $152.562 \pm 6.103$ \\
L1/L2 intervertebral joint $\left(^{\circ}\right)$ & $13.742 \pm 2.794^{\mathrm{b}}$ & $11.540 \pm 2.543^{\mathrm{a}}$ & $12.322 \pm 3.234$ \\
L5/S1 intervertebral joint $\left(^{\circ}\right)$ & $15.273 \pm 3.627^{\mathrm{b}}$ & $13.574 \pm 3.643^{\mathrm{a}}$ & $14.520 \pm 3.773$ \\
\hline
\end{tabular}

Values are the means $\pm \mathrm{SD},{ }^{*} \mathrm{p}<.05$

asignificant difference relative to ground condition

${ }^{\mathrm{b}}$ significance difference relative to platform condition
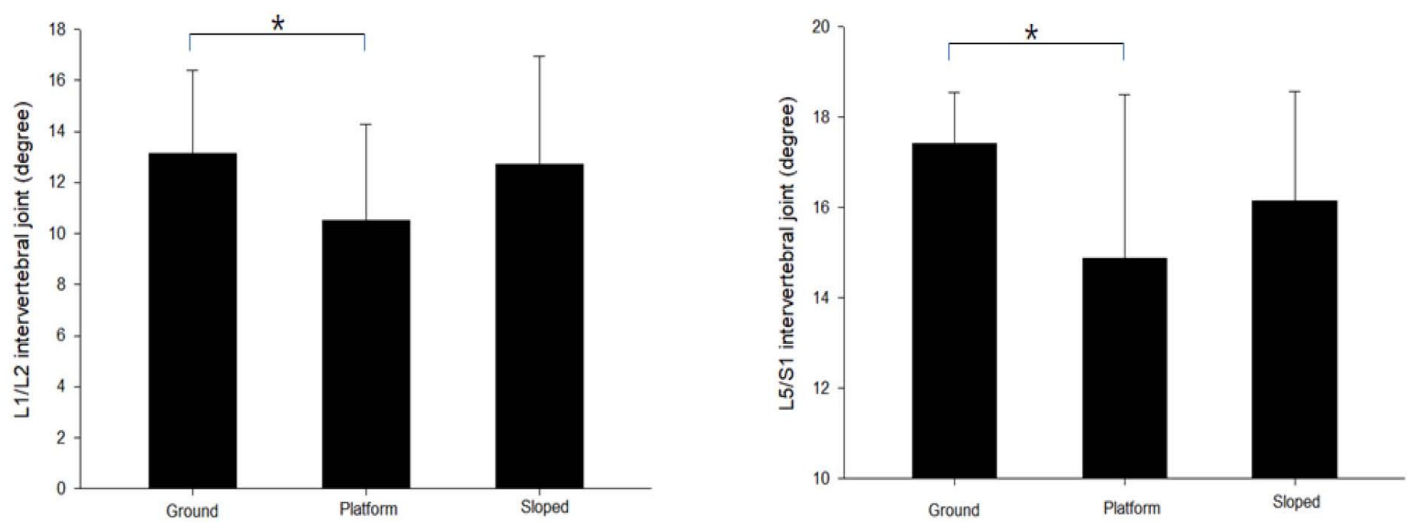

Fig. 5. Intervertebral joint angle in three standing conditions

Table 2. Co-contraction Index for Each Standing Condition

\begin{tabular}{ccc}
\hline Standing condition & LLES-RLES & RGM-LGM \\
\hline Ground & $53.913 \pm 19.562^{\mathrm{b}, \mathrm{c}}$ & $60.642 \pm 26.144^{\mathrm{b}, \mathrm{c}}$ \\
Platform & $32.612 \pm 14.084^{\mathrm{a}}$ & $40.833 \pm 22.834^{\mathrm{a}}$ \\
Sloped & $35.083 \pm 22.675^{\mathrm{a}}$ & $43.483 \pm 21.125^{\mathrm{a}}$ \\
\hline
\end{tabular}

Values are the means $\pm \mathrm{SD},{ }^{*} \mathrm{p}<.05$, LLES: left lumbar erector spinae, RLES: right lumbar erector spinae, RGM: right gluteus medius, LGM: left gluteus medius

${ }^{\text {a }}$ Significant difference relative to ground condition

${ }^{\mathrm{b}}$ Significant difference relative to platform condition

${ }^{\mathrm{c}}$ Significant difference relative to sloped condition

\section{Discussion}

Posture during work is important because it affects the ability to work over a prolonged duration without musculoskeletal disorder, fatigue, and discomfort. The present study was conducted to examine the co-contraction of lumbar and hip muscles and lumbar lordosis while standing with the use of standing aids to identify a desirable standing posture.

Differences in alignment were observed for the upper and lower lumbar spine. Previous studies showed that there were differences between the upper and lower lumbar lord 

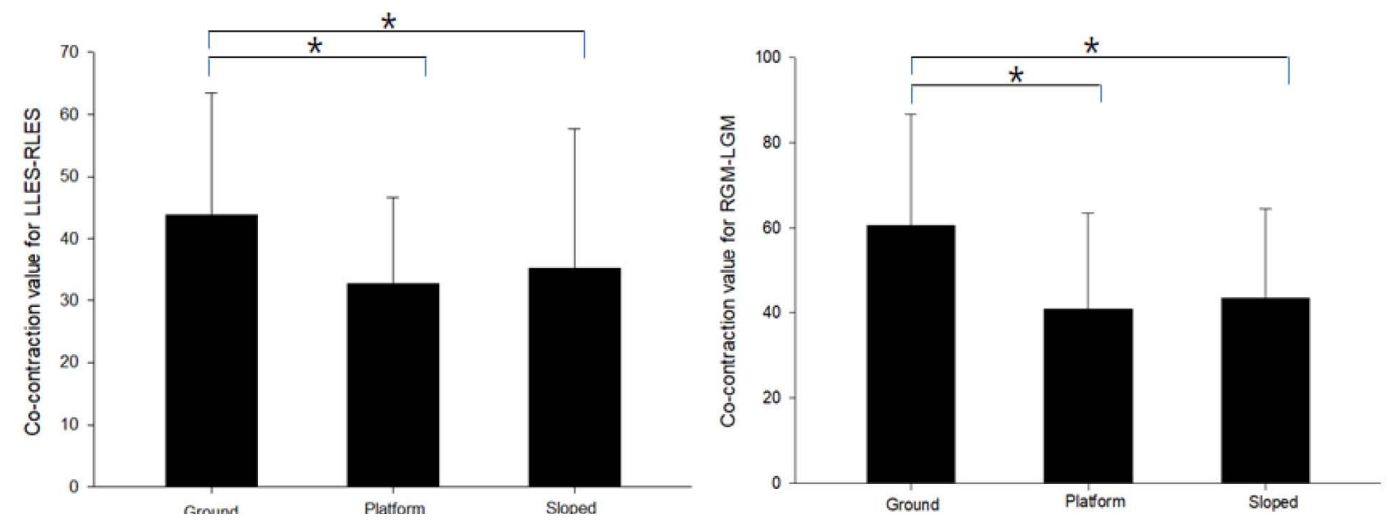

Fig. 6. Co-contraction values for RLES-LLES, RGM-LGM

osis angle [17]. The lumbar spine angle measured with one foot on a platform was the closest to the neutral zone owing to the lumbar spine flexion. When the lumbar spine is in the neutral zone contact between facet joints, stretching of facet joint capsules, and impingement between the facet joint and spinous process is minimized, which tends prevents pain from occurring [18]. This is because the level of elastic strain is higher in the standing posture of individuals with a hyperlordotic spine than that of individuals with a hypolordotic spine, resulting in a greater moment load in the lumbar area [19]. No significant differences were found between standing on a sloped surface and standing on level ground, but lumbar spine flexion showed an increasing tendency in the former posture. Hip and trunk flexion occurred because the trunk, lumbar spine, and pelvis work together as a functional unit during standing on a sloped surface, but with relatively little change in the alignment of the lumbar spine [14]. Contrary to the findings of the present study, the use of a sloped surface has been reported to increase the lumbar flexion angle and decrease the incidence of LBP by $59.4 \%$.

In this study, we hypothesized that bilateral weight shifting during prolonged standing would prevent pain because the lumbar and hip muscles on the side from which weight load was shifted away were relaxed [20]. In a study that investigated the muscle activation pattern in individuals with LBP, increased muscle co-contraction was found to increase the load on the lumbar spine. Using standing aids reduced co-contraction of the LES and GM in comparison with standing on level ground [9]. A study conducted to investigate the relationship between asymmetry in the hip extensor and LBP based on the muscle strength of the hip extensor indicated that asymmetry in the muscles causes LBP $[21,22]$. However, that study was based on muscle strength measurements and did not examine motor control or muscle activation patterns. Considering the results of a previous study that showed co-contraction of the LES and GM can be considered a motor control pattern that can predict the occurrence of LBP, a reduction of hip muscle co-contraction may have a positive outcome in individuals without LBP. In the present study, standing on a sloped surface did not change the angle of the lumbar spine flexion, but the level of GM co-contraction was low. It has been speculated that hip flexion during standing on a sloped surface stretches the posterior muscles, decreasing GM co-contraction by increasing passive force [4].

The results of the present study suggest the importance of the use of standing aids to standing posture. The use of standing aids can modify the movement patterns of the lumbar spine by changing muscle co-contraction. To prevent LBP, a good standing posture in combination with the use of standing aids is also important. Increased 
discomfort even with the use of standing aids indicates poor standing posture, in which case the use of standing aids will not help with prolonged standing.

\section{Conclusion}

This study demonstrated that standing with a foot on a platform induced lumbar lordosis, lumbosacral lordosis, and L5/S1 intervertebral joint flexion, but that there was no significant difference between standing on a sloped surface and standing on level ground. However, muscle co-contraction was reduced with the use of standing aids. When using motor control patterns as a predictor of LBP, the use of standing aids would help workers during prolonged standing.

\section{References}

[1] Airaksinen O, Brox JI, Cedraschi C, et al. Chapter 4. European guidelines for the management of chronic nonspecific low back pain. Eur Spine J. 2006;Suppl 2:S192-300

[2] Korean Ministry of Employment and Labor. Industrial accident. 2017.

[3] Kent P, Keating J. Do primary-care clinicians think that nonspecific low back pain is one condition?. Spine. 2004;29(9):1022-31.

[4] Nelson-Wong E, Callaghan JP. Is muscle co-activation a predisposing factor for low back pain development during standing? A multifactorial approach for early identification of at-risk individuals. J Electromyogr Kinesiol. 2010a;20(2):256-63.

[5] Marshall PW, Patel H, Callaghan JP. Gluteus medius strength, endurance, and co-activation in the development of low back pain during prolonged standing. Hum Mov Sci. 2011;30(1):63-73.

[6] Tissot F, Messing K, Stock S. Studying the relationship between low back pain and working postures among those who stand and those who sit most of the working day. Ergonomics. 2009;52(11):1402-18.

[7] Nelson-Wong E, Gregory DE, Winter DA, et al. Gluteus medius muscle activation patterns as a predictor of low back pain during standing. Clin Biomech. 2008a;23(5): 545-53.

[8] Winter DA, Prince F, Stergiou P, et al. Medial-lateral and anterior-posterior motor responses associated with centre of pressure changes in quiet standing. Neurosci Res Commun. 1993;12(3):141-8.

[9] Nelson-Wong E, Gregory DE, Winter DA, et al. Gender differences in postural control strategies during prolonged standing. In North American Conference on Biomechanics (NACOB), Ann Arbor, MI. 2008b.

[10] Konz SA, Rys MJ. An ergonomics approach to standing aids. Occup Ergon. 2003;3(3):165-72.

[11] Dolan P, Adams MA, Hutton WC. Commonly adopted postures and their effect on the lumbar spine. Spine. 1988;13(2):197-201.

[12] Gallagher KM, Callaghan JP. Standing on a declining surface reduces transient prolonged standing induced low back pain development. Appl. Ergon. 2016;56:76-83.

[13] Gallagher KM, Wong A, Callaghan JP. Possible mechanisms for the reduction of low back pain associated with standing on a sloped surface. Gait Posture. 2013; 27(3):313-8

[14] Nelson-Wong E, Callaghan JP. The impact of a sloped surface on low back pain during prolonged standing work: a biomechanical analysis. Appl Ergon. 2010;41(6):787-95.

[15] Chmielewski TL, Hurd WJ, Rudolph KS, et al. Perturbation training improves knee kinematics and reduces muscle co-contraction after complete unilateral anterior cruciate ligament rupture. Phys Ther. 2005;85(8):740-9.

[16] Keegan JJ. Alterations of the lumbar curve related to posture and seating. J Bone Joint Surg Am. 1953;35A(3):589-603

[17] Mitchell T, O'Sullivan PB, Burnett AF, et al. Regional differences in lumbar spinal posture and the influence 
of low back pain. BMC Musculoskelet Disord. 2008;9:152.

[18] Winkelstein BA, DeLeo JA. Mechanical thresholds for initiation and persistence of pain following nerve root injury: mechanical and chemical contributions at injury. J Biomech Eng. 2004;126(2):258-63.

[19] Scannell JP, McGill SM. Lumbar posture--should it, and can it, be modified? A study of passive tissue stiffness and lumbar position during activities of daily living. Phys Ther. 2003;83(10):907-17.

[20] Carlsöö S. The static muscle load in different work positions: An electromyographic study. Ergonomics. 1961;4(3):193-211.

[21] Kim CY, Kang JH. Analysis of electromyographic activities of erect spinae at different height of table during ultrasound therapy work. J Korean Soc Phys Med. 2013;12(3):1-10.

[22] Nadler SF, Malanga GA, Feinberg JH, et al. Relationship between hip muscle imbalance and occurrence of low back pain in collegiate athletes: a prospective study. Am J Phys Med Rehabil. 2001;80(8):572-7. 